\author{
Military Technical College \\ Kobry El-Kobbah, \\ Cairo, Egypt
}

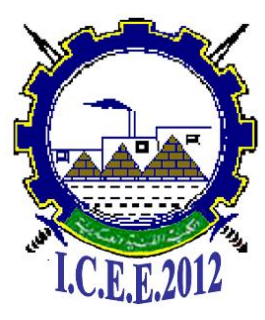

$6^{\text {th }}$ International Conference on

Chemical \& Environmental Engineering

29 - 31 May, 2012

\title{
CEEB-1
}

\section{RHEOLOGICAL BEHAVIOR OF LUBRICATING OIL WITH POLYACRYLATES COPOLYMERS}

\author{
Salah A. Mohamad*, Nehal S. Ahmed*, Saeed M. Hassanein ${ }^{* *}$ and Ahmed M. Rashad**
}

\begin{abstract}
Six copolymers based on acrylates were used as viscosity index improvers [1]. The effect of these copolymers on the rheological behavior such as viscosity thinning or thickening has been studied. A rheological study was carried out to SAE 30 base oil before and after adding the viscosity index improvers with different concentrations (1, 2, 3\% wt). Brookfield rheometer model (DV-III+) was used with different shear rates and at different temperatures $\left(40,60,100{ }^{\circ} \mathrm{C}\right)$, for characterization of the enhanced lubricant. It was noticed that Freeadditives Base oil exhibits a Newtonian behavior at all temperatures, on the other hand; all enhanced samples exhibit a weak non-Newtonian behavior that disappears with increasing either temperature or shear rate or both of them. The effect of temperature on specific viscosities of the blends under different shear rates was studied to determine the efficiency of viscosity index improvers and record its mechanism of action at different shear rates and temperatures.
\end{abstract}

\footnotetext{
* National Petroleum Research Institute ( NPRI)

E** Egytian Armed Forces
} 


\section{Introduction}

Rheology may be described as a compound's response to a stress applied on the material during production, processing, and/or application. Rheology measures the change in viscosity of a substance under changing shear rates or a change in viscosity over time at a constant shear rate. The rheology, or flow, of a compound may be classified as Newtonian, psuedoplastic, thixotropic, or dilatant, based on the measured response of the compound to a known shear rate, compared to classical models. Newtonian flow describes a compound that exhibits no change in viscosity with increasing shear rate. A classical example of a compound with Newtonian behavior is water. Psuedoplastic flow describes a system that exhibits a reduction in viscosity with increasing shear rate. The viscosity will recover as the shear is removed; though it may not follow the same viscosity profile as exhibited with increasing shear. This type of flow is also referred to as shear thinning. Most acrylates provide psuedoplastic behavior [2]. Figures (1) through (3) shows a rheological study of Polymethacrylates that has been carried out by M.H.M. Hassanean [4]. The blends have been studied at different temperatures and shear rates and the results showed the same behavior.

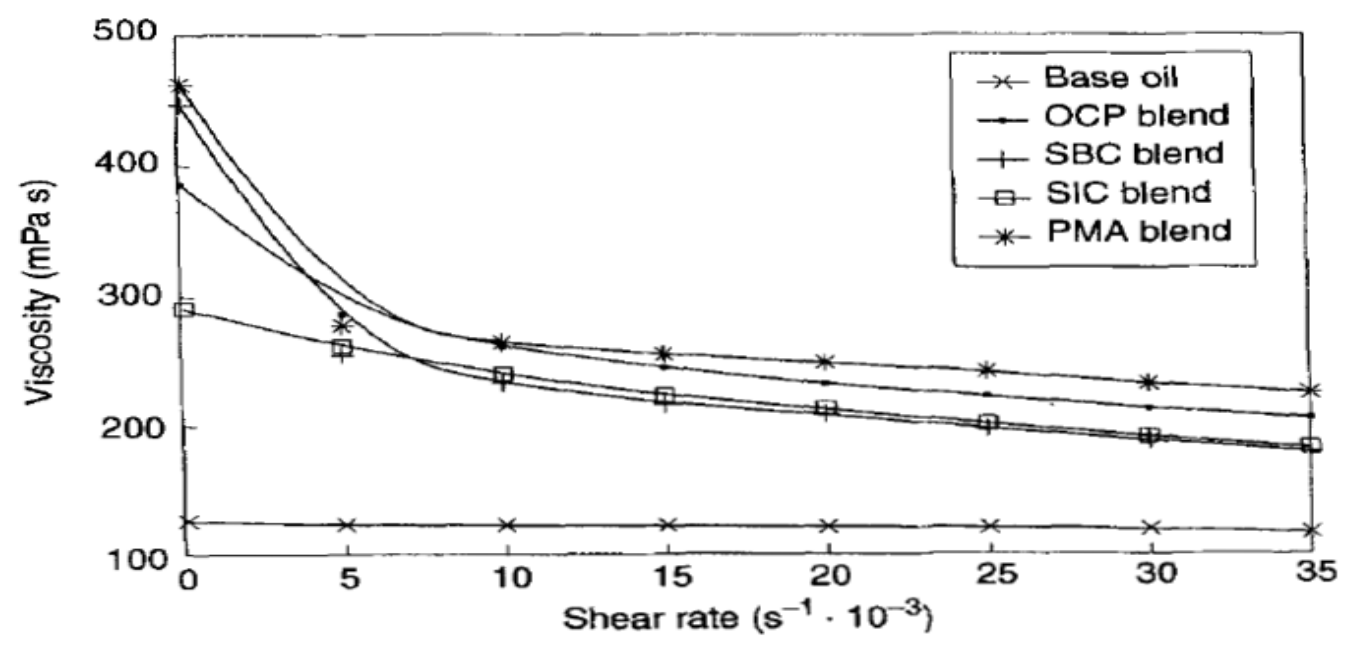

Fig (1) Change in dynamic viscosity with increasing shear rate at $25^{\circ} \mathrm{C}$ for tested SAE 50 blends [4]. 


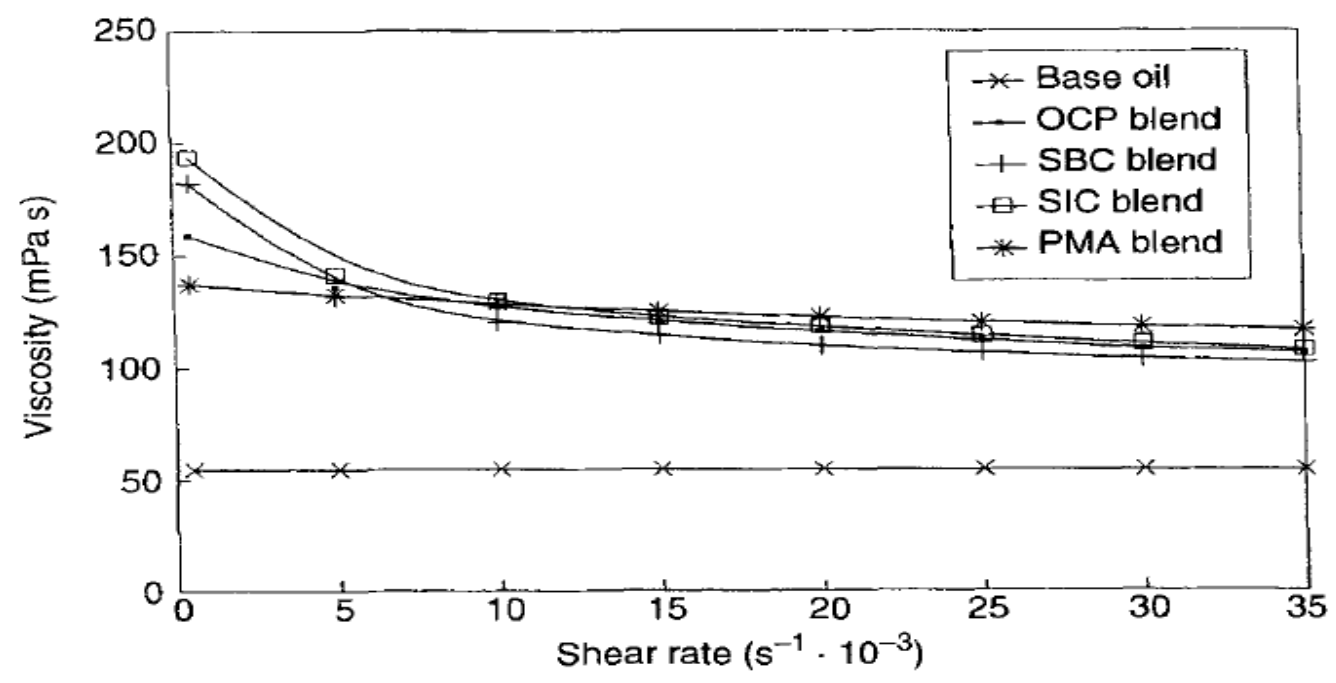

Fig (2) Change in dynamic viscosity with increasing shear $\mathrm{t} 40^{\circ} \mathrm{C}$ for tested SAE 50 blends [4].

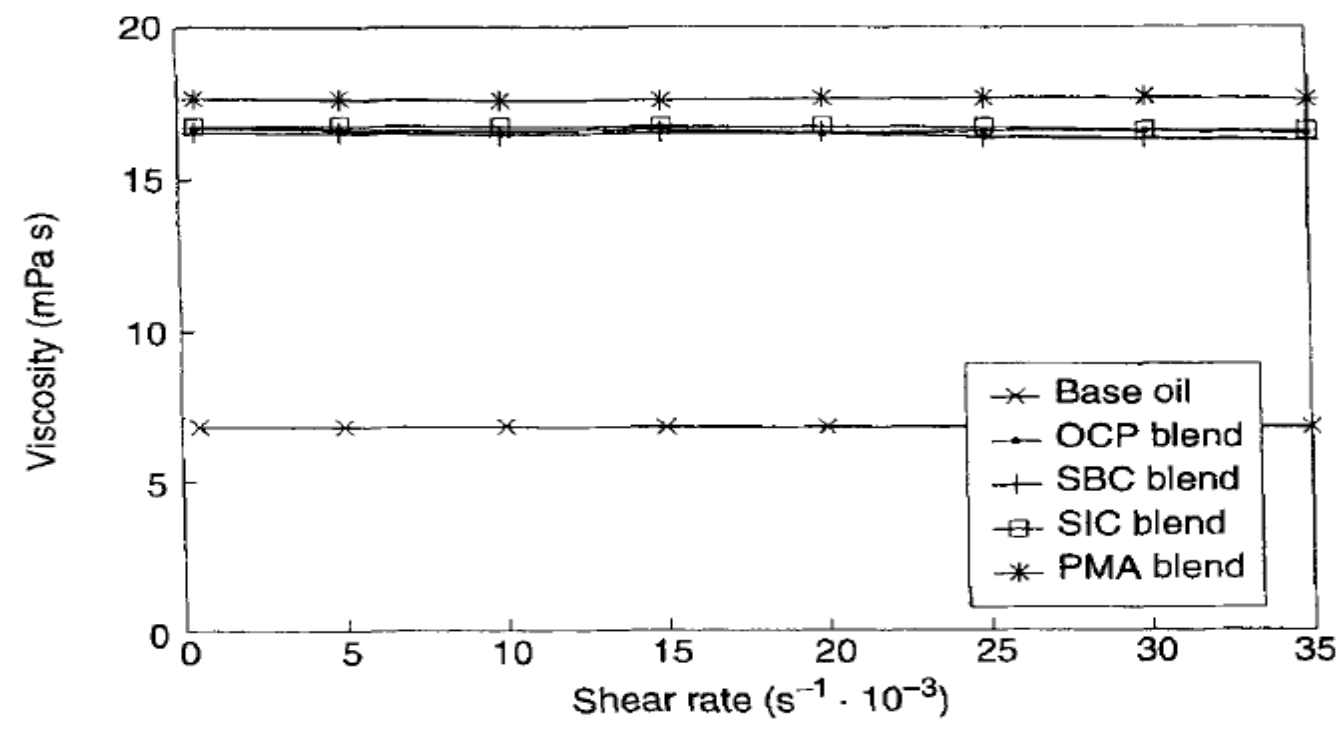

Fig 3 Change in dynamic viscosity with increasing shear rate at $100^{\circ} \mathrm{C}$ for tested SAE 50 blends [4].

Dilatant, or shear thickening flow exhibits an increase in viscosity with increasing shear rate, and is generally an indication of instability in a system. When the stress imparted on a system becomes excessive, the particles begin to grind against one another, resulting in an increase in viscosity. While this type of behavior may be desirable for a specific application, it is a disadvantage in lubricants, as the oil would thicken when pumped causing lines of lubricating system to plug [3]. 
Too high viscosity engine lubricant can create viscous drag. This generates more friction which in turn generates more heat. Energy or power losses and poor cold starting pumpability can also all resulted from lubricant over-thickening [4]. However, too low viscosity is not desirable too, as it causes excessive wear due to the loss of the load bearing characteristics of the oil. One of the functions of a lubricant is to act as a seal; low viscosity oil does not make a good seal, so both internal and external leakage may be a problem. Finally, hydrodynamic film is dependent on high speed, high viscosity, and low load. This means that if the viscosity is low, then the high load and/or low speed applications may result in lubricant film failure [5].

So, shear, and thermal stability are strongly required for the lubricating oils and that can be achieved by V.I improvers. Copolymers used as VI improvers should be evaluated from rheological point of view. In the present work, rheological characterization for a group of copolymers (polyacrylates) which used as VI improvers, has been carried out using Brookfield rheometer model (DV-III+) by applying variable shear rates ranging from 5 to 40 $\mathrm{s}^{-1}$ under constant temperatures, $40^{\circ} \mathrm{C}, 60^{\circ} \mathrm{C}$, and $100^{\circ} \mathrm{C}$. Three concentrations $(1 \mathrm{wt} \%, 2 \mathrm{wt}$ $\%, 3$ wt \%) per additive were used to study the effect of polymer concentration on the rheological behavior.

\section{Experimental}

Six Polyacrylates viscosity index improvers have been prepared in several steps, starting from esterification of acrylic acid and alcohols, purification of produced esters, identification of the purified esters, polymerization of produced esters, and finally characterization of the produced copolymers by solubility test and molecular weight determination. Constituents of the prepared copolymers and their designations are listed in table (1).

\begin{tabular}{|l|l|l|}
\hline Polymer Code & Compounds Used \\
\hline A (C8_C10) & Octyl Acrylate & Decyl Acrylate \\
\hline B (C8_C12) & Octyl Acrylate & Dodecyl Acrylate \\
\hline C (C8_C14) & Octyl Acrylate & tetradecyl Acrylate \\
\hline D (C8_C16) & Octyl Acrylate & Hexadecyl Acrylate \\
\hline E (C12_C16) & Dodecyl Acrylate & Hexadecyl Acrylate \\
\hline F (C10_C16) & Decyl Acrylate & Hexadecyl Acrylate \\
\hline
\end{tabular}

Table (1) Constituents of the prepared copolymers and their designations 


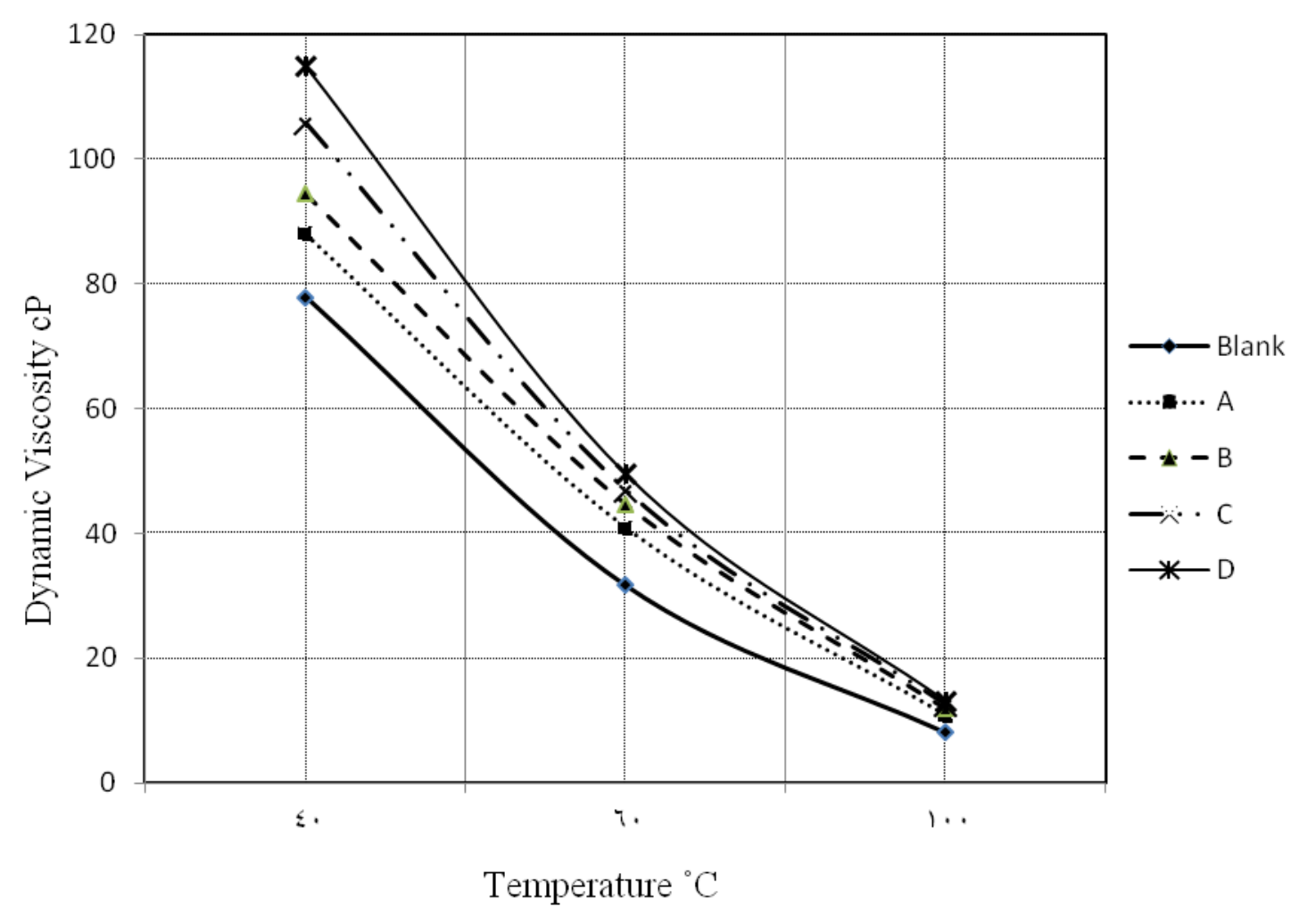

Fig. (4) Effect of temperature on viscosity of oil samples und same shear rates and additives concentration $3 \% \mathrm{wt}$.

Figure (4) shows the effect of temperature on the viscosity of SAE30 lubricating oil with polyacrylates VI improvers at $3 \%$ wt concentration.

The rheological behavior of the prepared improved lubricants was carried out using Brookfield digital rheometer model (DV-III+). The rheometer measures liquids' shear stress and viscosity at given shear rates. The principle of operation of the (DV-III+) is to drive a spindle (which is immersed in the test fluid) through a calibrated spring. The viscous drag of the fluid against the spindle is measured by the spring deflection. Spring deflection is measured with a rotary transducer. The measuring range of the rheometer (in centipoise) is determined by the rotational speed of the spindle, the size and shape of the spindle, the container where the spindle is rotating in, and the full scale torque of the calibrated spring viscosity appears in units of centipoise (shown as "cP") or milliPascal-seconds (shown as $\mathrm{mPa} . \mathrm{s})$. Shear Stress appears in units of $\left(\mathrm{N} / \mathrm{m}^{2}\right)$. Shear rate appears in units of reciprocal seconds $(1 / \mathrm{s})$. Torque appears in units of Newton-meters (shown as percent "\%" in both cases). Spring torque less than $10 \%$ may cause an error in the results, when it is greater than $100 \%$ program displays (EEEE) which means error in the measurement procedure. In such case, changing the spindle may be recommended. A small liquid cell is attached to the rheometer and is connected to a circulator thermostat by silicon hoses to control cell's temperature during measurement.

The rheological behavior of SAE30 crude oil with different additives for concentrations 0 , $1 \%, 2 \%$, and $3 \%$ by weight were studied at temperatures $40^{\circ} \mathrm{C}$ with shear rates ranging from 5 to $40 \mathrm{~s}^{-1}, 60^{\circ} \mathrm{C}$ with the same range of shear rates, and $100^{\circ} \mathrm{C}$ with higher shear rate ranging 
from 50 up to $250 \mathrm{~s}^{-1}$. The low shear rates were applied at $40^{\circ} \mathrm{C}$ and $60^{\circ} \mathrm{C}$ because it is noticed that the effect of shear on oil appears at low shear rates and it is not any more at higher shear rates. The higher shear rates were applied at $100^{\circ} \mathrm{C}$ because at such temperature the polymers in oil suffer minimum shear thinning at low shear rates. That has been noticed in less than $10 \%$ torque displayed by the rheometer screen when applying low shear rates using the largest size spindle at $100^{\circ} \mathrm{C}$.

Specific viscosity is then determined for the tested blends at different temperatures $(40,60$, and $100{ }^{\circ} \mathrm{C}$ ) once under low shear rates $\left(5-10 \mathrm{~s}^{-1}\right)$ and another time at high shear rates (up to $250 \mathrm{~s}^{-1)}$.

Specific viscosity can be defined as [3]:

$$
V_{s p}=\frac{V_{p}-V_{o}}{V_{o}}
$$

Where: $\mathrm{V}_{\mathrm{p}} \quad$ Viscosity of VIIs-oil blend.

$\mathrm{V}_{\mathrm{o}} \quad$ Viscosity of oil.

\section{Results and Discussion}

Figures (3-8) shows the effect of shear rate on the dynamic viscosity at different viscosity index improvers' concentrations $(1 \%, 2 \%$, and $3 \% \mathrm{wt})$ of additives and different temperatures $\left(40^{\circ} \mathrm{C}, 60^{\circ} \mathrm{C}\right.$, and $\left.100^{\circ} \mathrm{C}\right)$. Blank sample was found to behave as Newtonian fluid for all shear rates. For oil samples with additives, it is clear that, at low shear rates (5-10 $\left.\mathrm{s}^{-1}\right)$; all blends have weak non-Newtonian behavior represented as shear thinning which is described as pseudoplastic behavior. As shear rate increases, the non-Newtonian behavior disappears and all blends behave as a Newtonian fluid. Non-Newtonian behavior exists for a very narrow range of shear rates at the starting of torque application, and then it is changed to Newtonian behavior for a wide range of higher shear rates. Polyacrylates are not associative VI improvers, and don't experience viscosity losses through loss of molecular associations in high shear stress fields [6]. Any loss of viscosity is related to the molecular size and the distortion of the molecules to occupy lower hydrodynamic volumes (see figure 5).

Viscosity index improvers exists in the fluid as bundles or tubes of long chain polymers, At low temperatures, that chains take spherical coils form that have random orientations under no shear. As mechanical shear is applied on the polymer containing oil, the random oriented unextraxted micelles tend to rearrange itself in the flow direction. That reorientation consumes mechanical energy which appears in higher resistance to spindle rotation; hence a temporary high viscosity of the oil at low shear rates is recorded.

The high value of the dynamic viscosity drops rapidly as shear rate increases because all of polymer macromolecules have been arranged in the direction of flow (see Fig. 6), hence there are no energy losses any more. That is clear from the negligible change in viscosity and the Newtonian behavior as shear increases. Due to the very small range of non-Newtonian behavior, all blends can be described nearly as Newtonian fluids because all operating conditions are at high shear rates. The base oil does not have any polymeric additives, so it does not experience any change in viscosity with changing shear rate. 


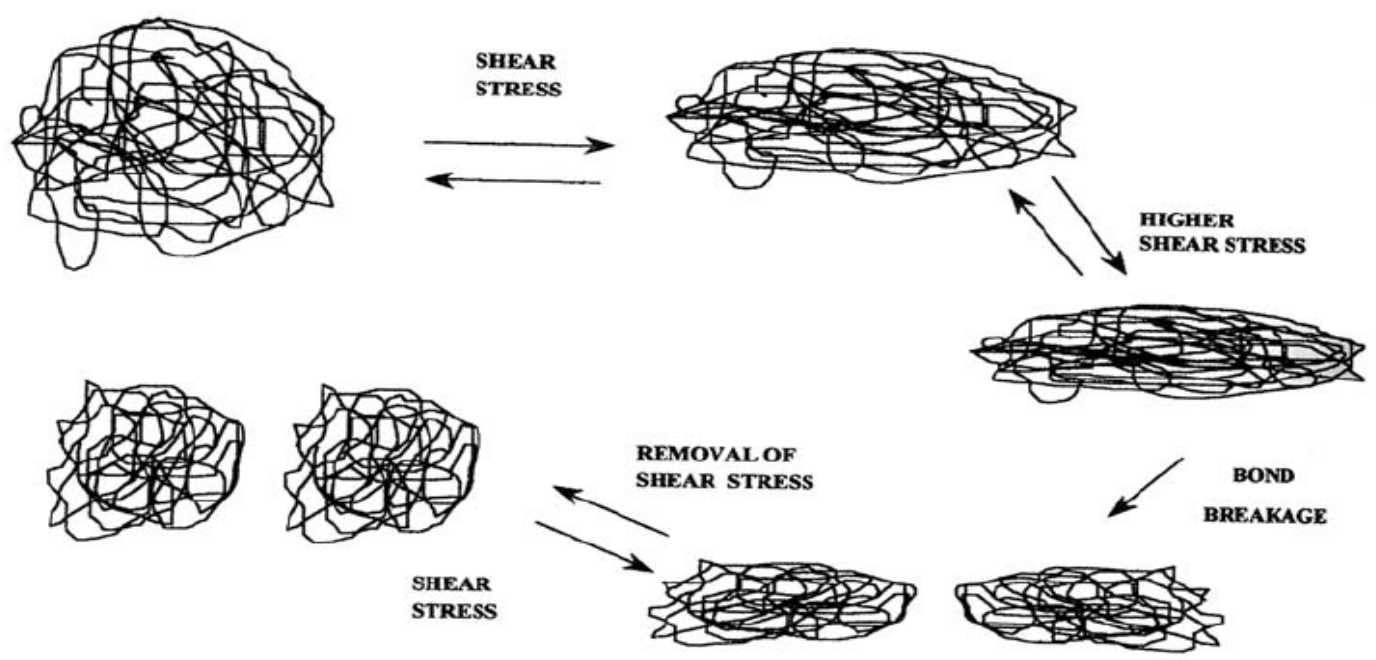

Fig. (5) Temporary and permanent shearing of the polymeric coils[6]
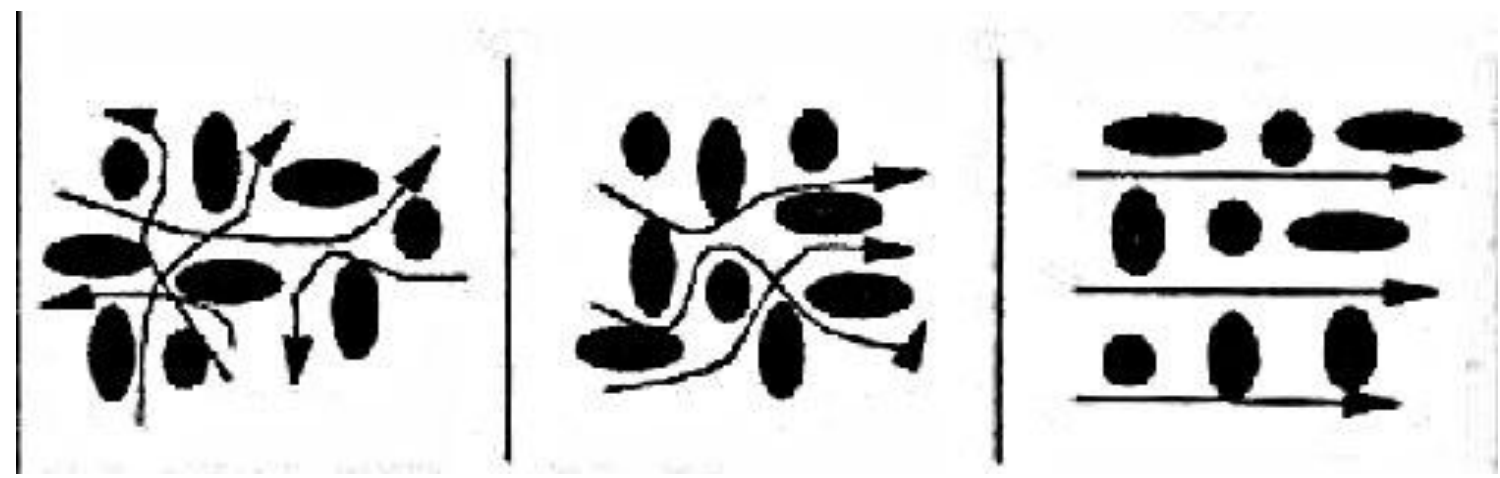
(a) Starting.
(b) Transient condition.
(c) Steady state condition

Fig. (6) Regimes of temporary shear thinning[6]

\subsubsection{Effect of temperature on rheological behavior of the tested blends}

From figures (7-12) it is obvious that the tested blends exhibit a weak non-Newtonian behavior only at low and moderate temperatures (not more than $60^{\circ} \mathrm{C}$ ) and low shear rates (not more than $\left.10 \mathrm{~s}^{-1}\right)$. At $\left(100^{\circ} \mathrm{C}\right)$, the tested blends behave as Newtonian fluids within the all ranges of shear rates. The specific viscosity is also plotted against the operating temperatures (see Figs.13 and 14). 


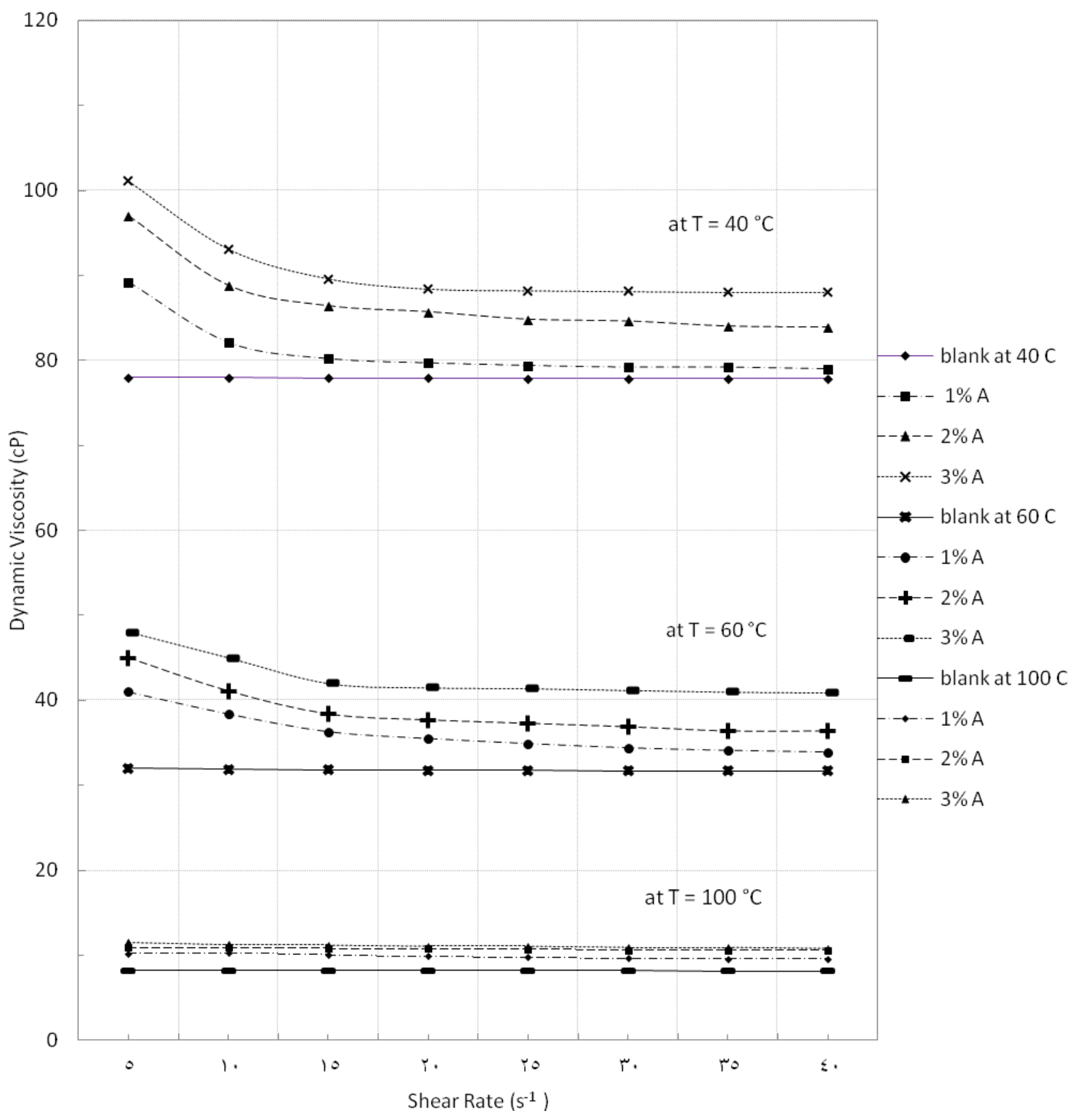

Fig. (3) Effect of shear rate on the dynamic viscosity of oil in presence of the copolymer A 


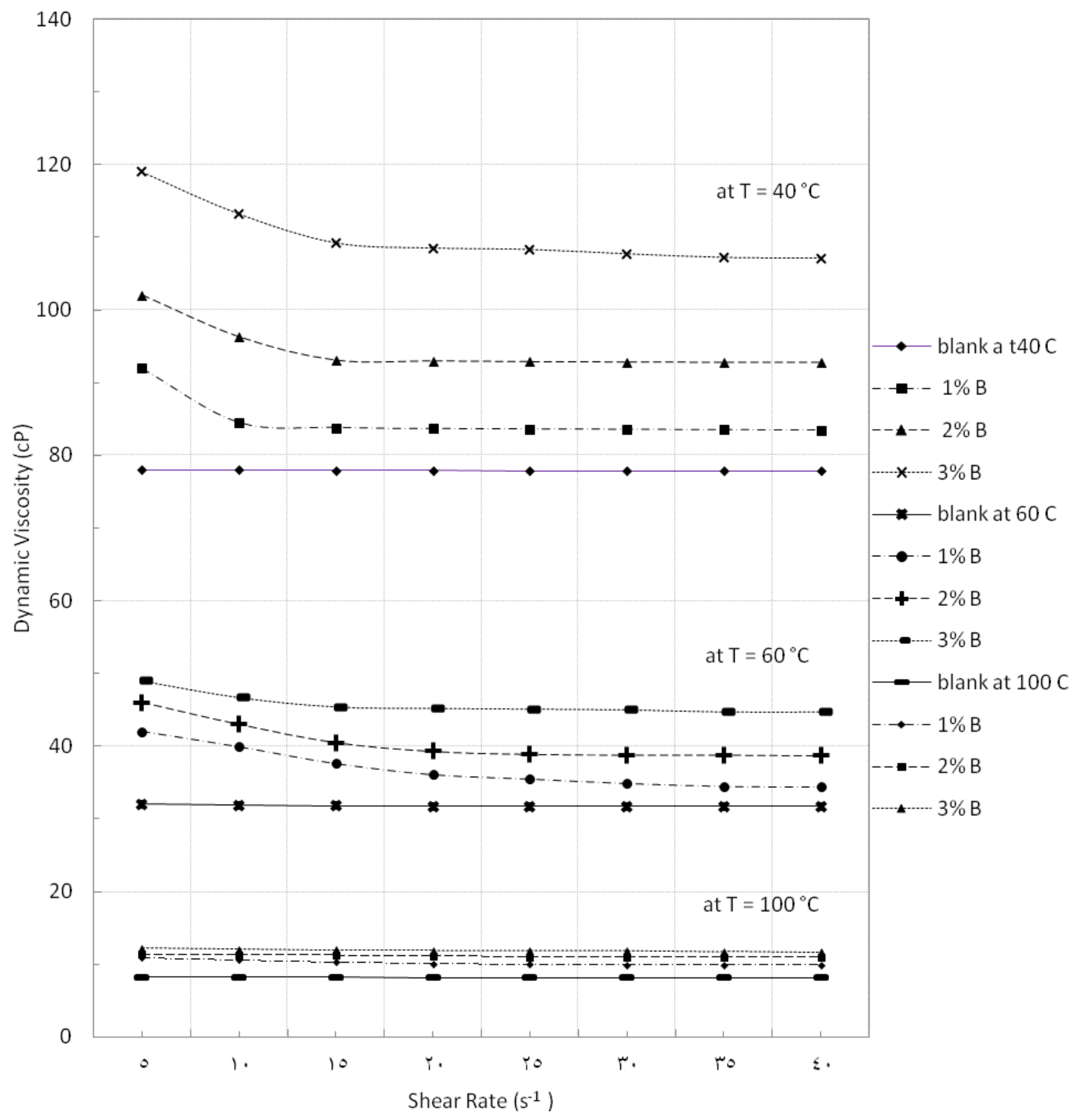

Fig. (4) Effect of shear rate on the dynamic viscosity of oil in presence of the copolymer B 


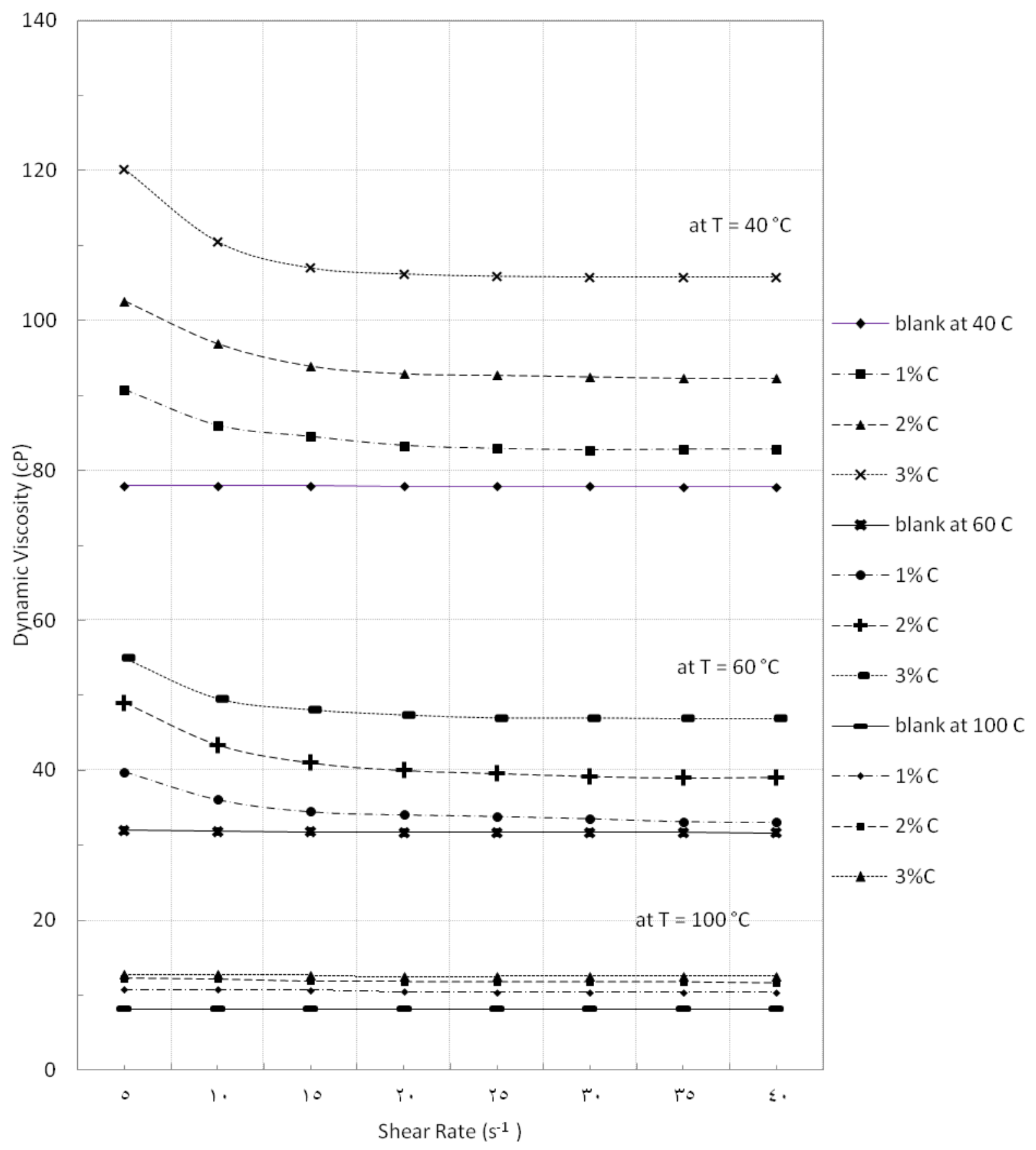

Fig. (5) Effect of shear rate on the dynamic viscosity of oil in presence of the copolymer C 


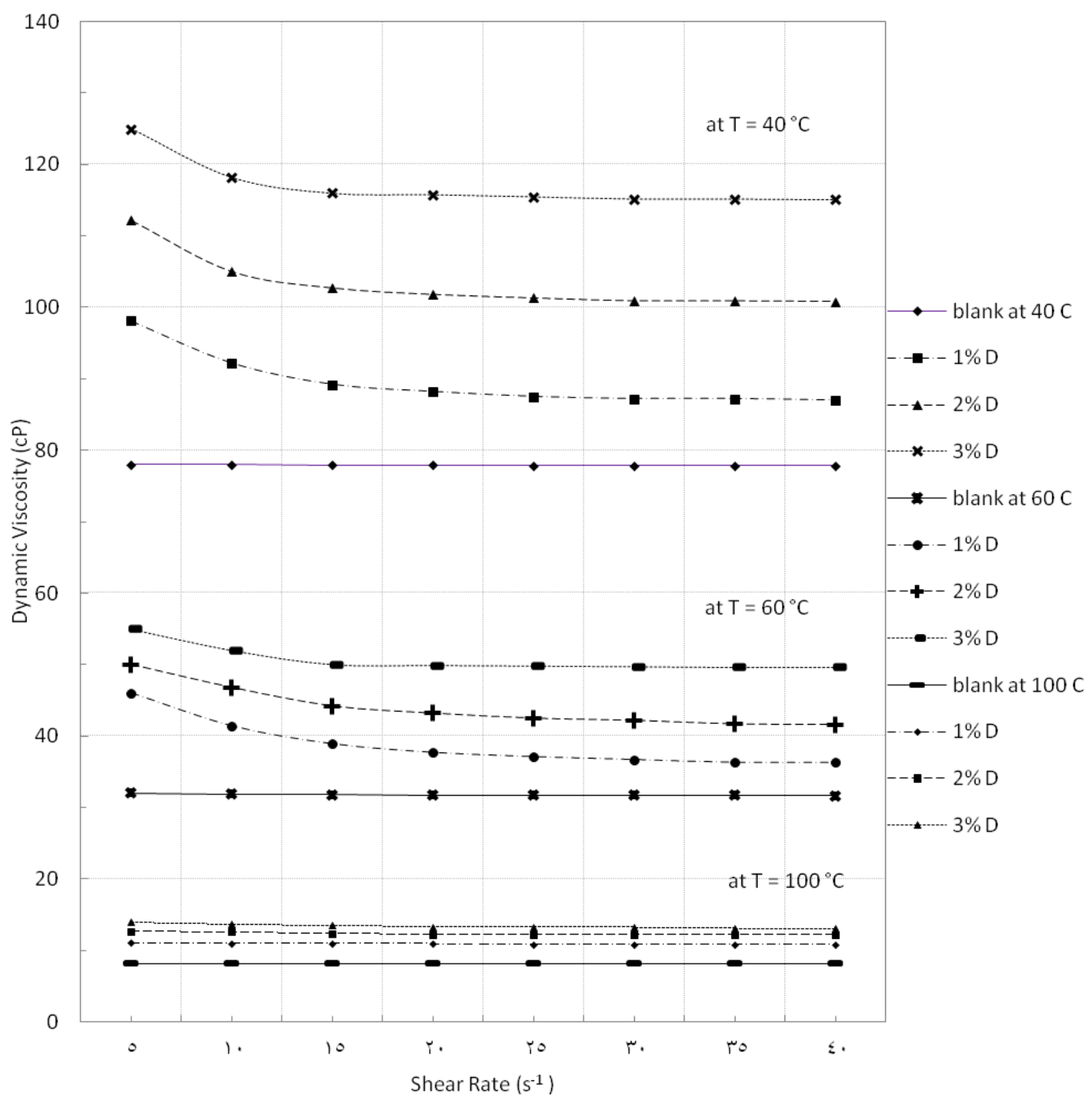

Fig. (6) Effect of shear rate on the dynamic viscosity of oil in presence of the copolymer D 


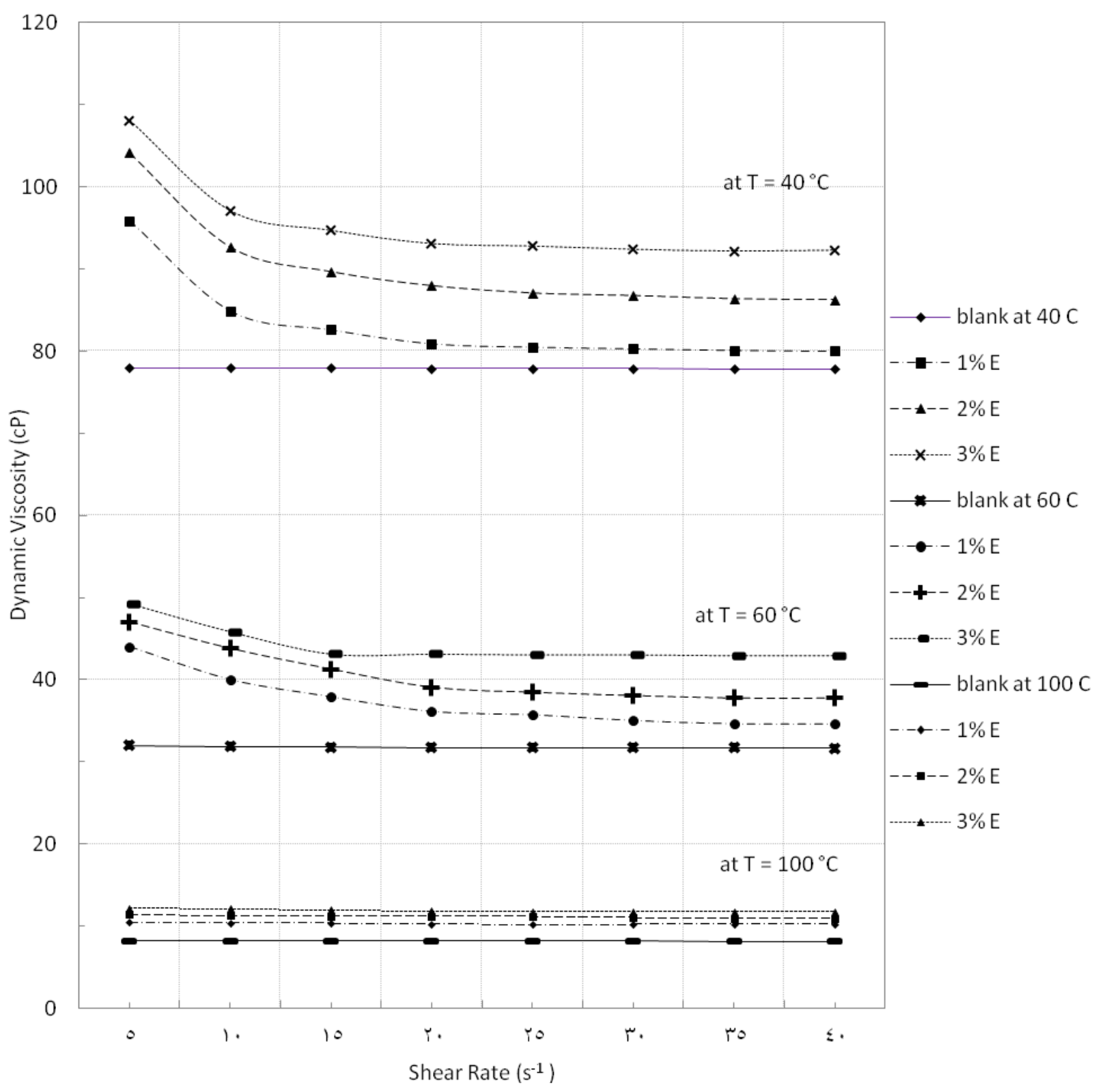

Fig. (7) Effect of shear rate on the dynamic viscosity of oil in presence of the copolymer E 


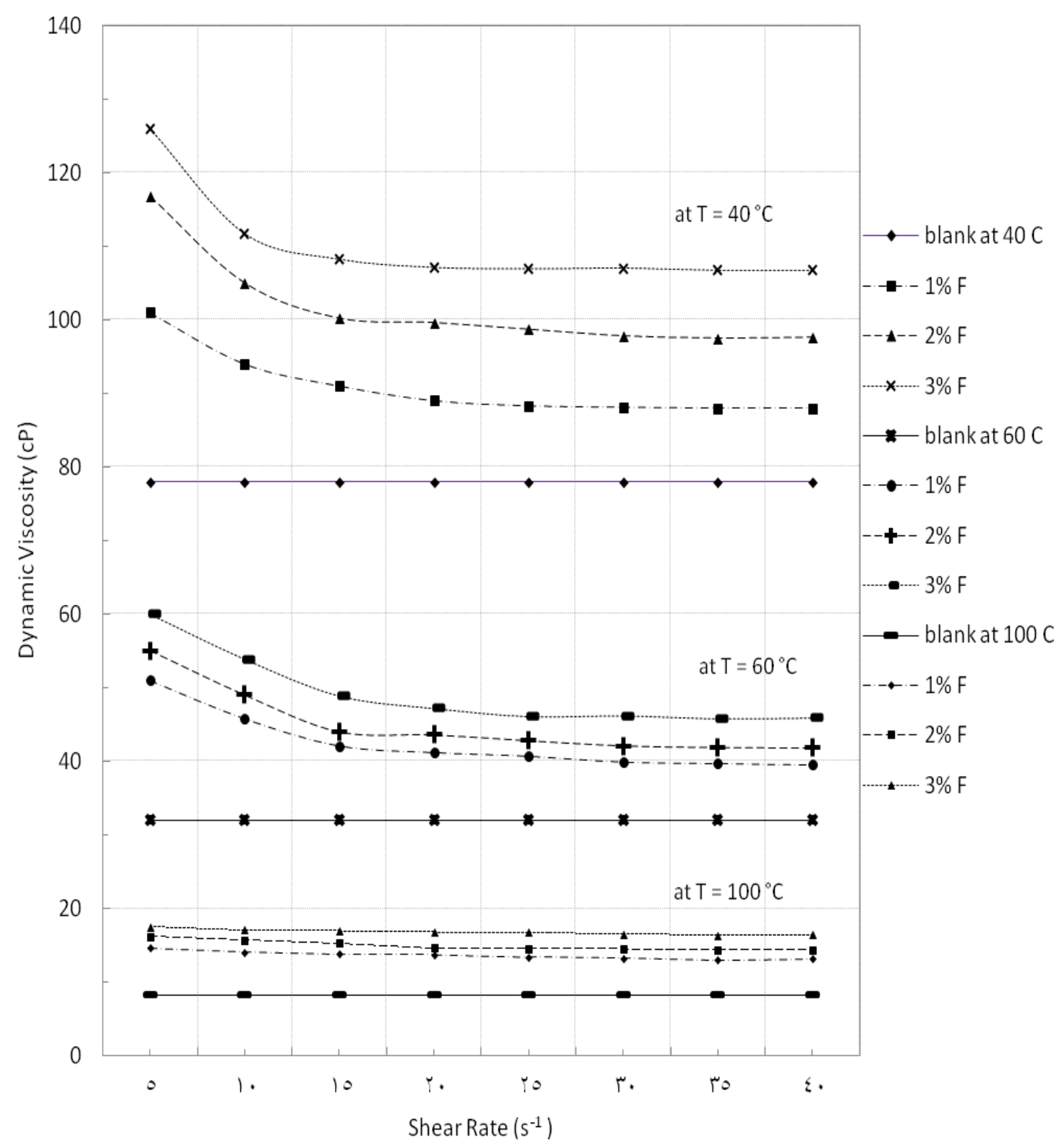

Fig. (8) Effect of shear rate on the dynamic viscosity of oil in presence of the copolymer F

\subsubsection{Effect of temperature on specific viscosity of the blends under low shear rates}

Fig. (13) shows the effect of temperature on the specific viscosity of the tested blend under low shear rates. At starting conditions, the copolymers exist at the spherical coiled form. As the shear stress applied, copolymer molecules reorient themselves along the axis of flow. That process requires relatively high energy at low temperature, which makes the specific viscosity increase at temperatures up to $60^{\circ} \mathrm{C}$. As temperature increases, the molecules shape changes from spherical coils to an elongated configuration, see Fig. (1), until the copolymeric molecules became completely expanded at high temperature, hence occupy smaller hydrodynamic volume and thus contributes less viscosity, but the effect of VI improvers 
compensate, relatively, that drop in viscosity, which explain the specific viscosity behavior at higher temperature (up to $100^{\circ} \mathrm{C}$ ).

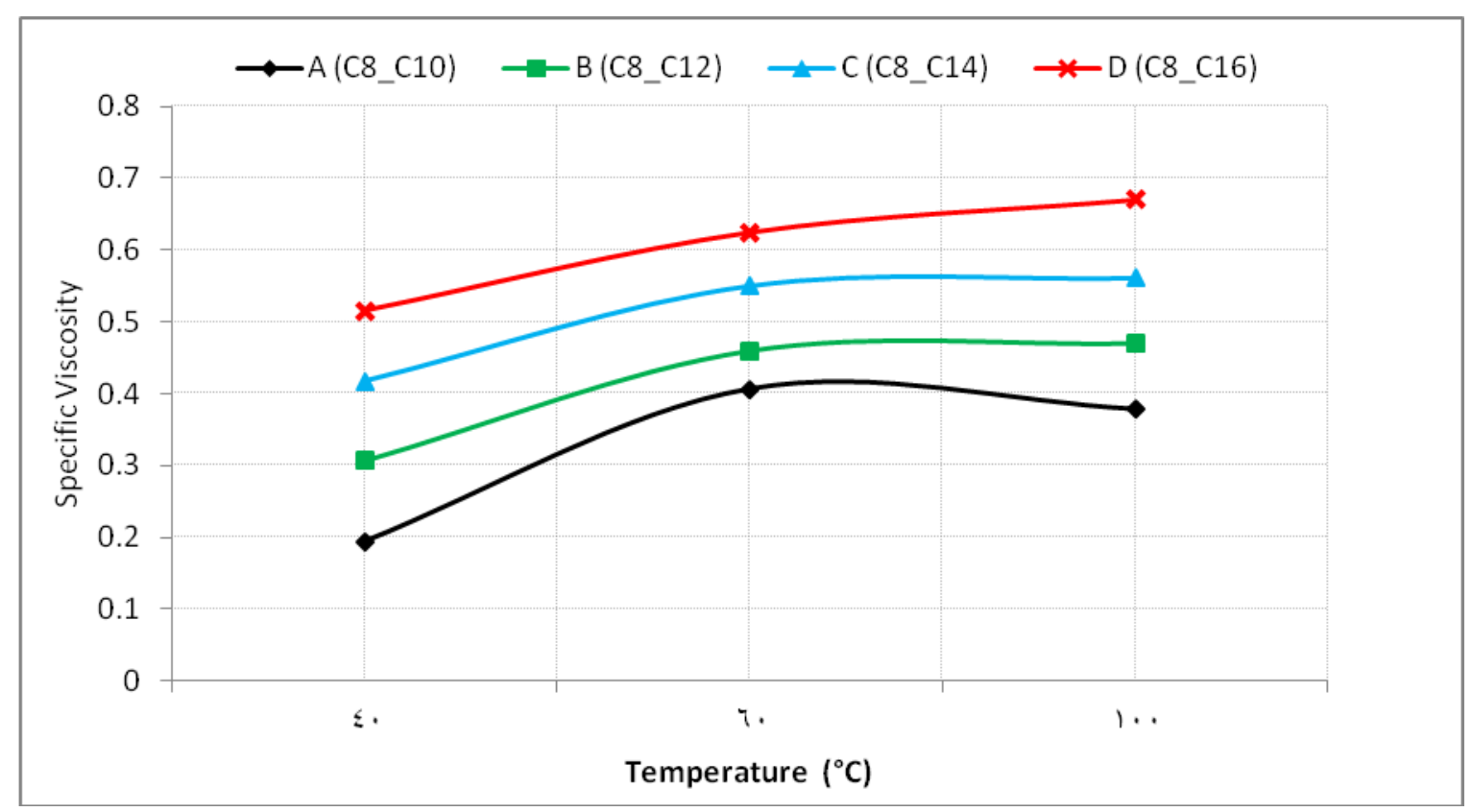

Fig. (13) Effect of temperature on specific viscosity of the blends under low shear rates (simulation of the starting conditions).

\subsubsection{Effect of temperature on specific viscosity of the blends under high shear rates}

Fig (14) shows the effect of temperature on the specific viscosity at high shear rate. All blend specific viscosities increase as temperature increases, and that is an indication for viscosity index improvement. At low temperatures, large macromolecules are affected by shear rates, so they orient themselves rapidly to the shear axis of flow. Accordingly, specific viscosities of all blends decrease.

At some high temperatures, V.I improvers acts freely due to existence of all polymers molecule in the full expanded form so, the specific viscosities increase with increasing shear rate. So, all additives are efficient as V.I improvers at the tested range of shear rate. 


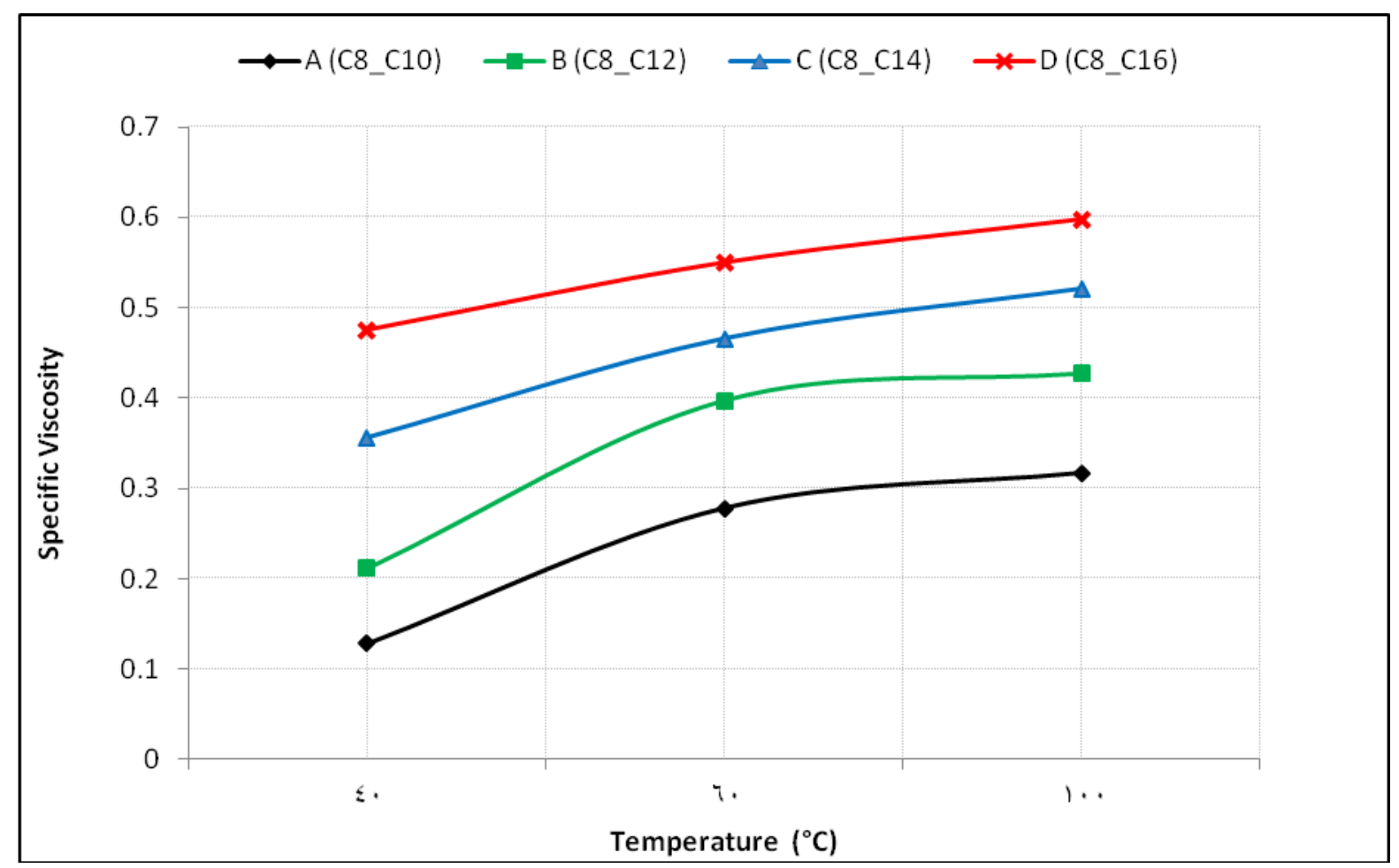

Fig. (14) Effect of temperature on specific viscosity of the blends under high shear rates (simulation of the running conditions). 


\section{Conclusion}

Six polyacrylates copolymer, used as viscosity index improvers, have been tested to evaluate their effect on the rheological behavior of SAE30 engine oil. The results showed that:

- Although these copolymers are used as viscosity index improvers, they have further effect on the rheological behavior of SAE30 lubricating oil.

- Base oil exhibits a Newtonian behavior under all ranges of shear rates

- All additives-containing oil samples exhibit pseudoplastic behavior, specially at low shear rates. As shear rate increases the oil tends to exhibit a Newtonian behavior. That simple drop at the starting vanishes as the temperature increases and completely disappears at $100^{\circ} \mathrm{C}$

All additives have thickening effect especially at high concentrations.

\section{References}

[1] Salah A. Mohamad, Nehal S. Ahmed, Saeed M. Hassanein and Ahmed M. Rashad, "Polyacrylates Copolymers as Lube Oil Viscosity Index Improvers", Accepted for puplication in journal of PetroleumScience and Technology, (2011).

[2] Lochhead, R.Y., "Water-Soluble/Water-Dispersible Copolymers Short Course", Sec. 7, pp. 74, May 23 (1994).

[3] A. Jukić, L.J. Tomašek, and Z.Janović, "Polyolefin and Poly(alkyl Methacrylate) Mixed Additives as Mineral Lubricating Oil Rheology Modifier", Lubrication Science 17-4, pp 431-449, (2005).

[4] M.H.M. Hassanean, W.J. Bartz, H.H. Abou El Naga, "A Study of the Rheological Behaviour of Multigrade Oil", Lubrication Science 10-1, pp 43-58, (1997).

[5] John S. Evans, B.Sc, "Ups and Downs of Viscosity", Technical Bulletin, (2007).

[6] Leslie R. Rudnick, "Lubricant Additives; chemistry and applications", Marcel Dekker, Inc., pp. 329-353, (2003). 